\title{
College Student Wellness
}

Asma Fuad Saleh

The daily life of a college student can be overwhelming with work and deadline, but the prioritization of an individual's health never changes. It is imperative for students to take a break when necessary and organize their time in a manageable and healthy style. Creating a routine and staying up-todate on all the necessary vaccinations and immunization shots is imperative to ones health. The diet and fitness of a student not only affects their physical well-being, but their mental health as well, which in turn, can affect their ability to study and learn effectively.
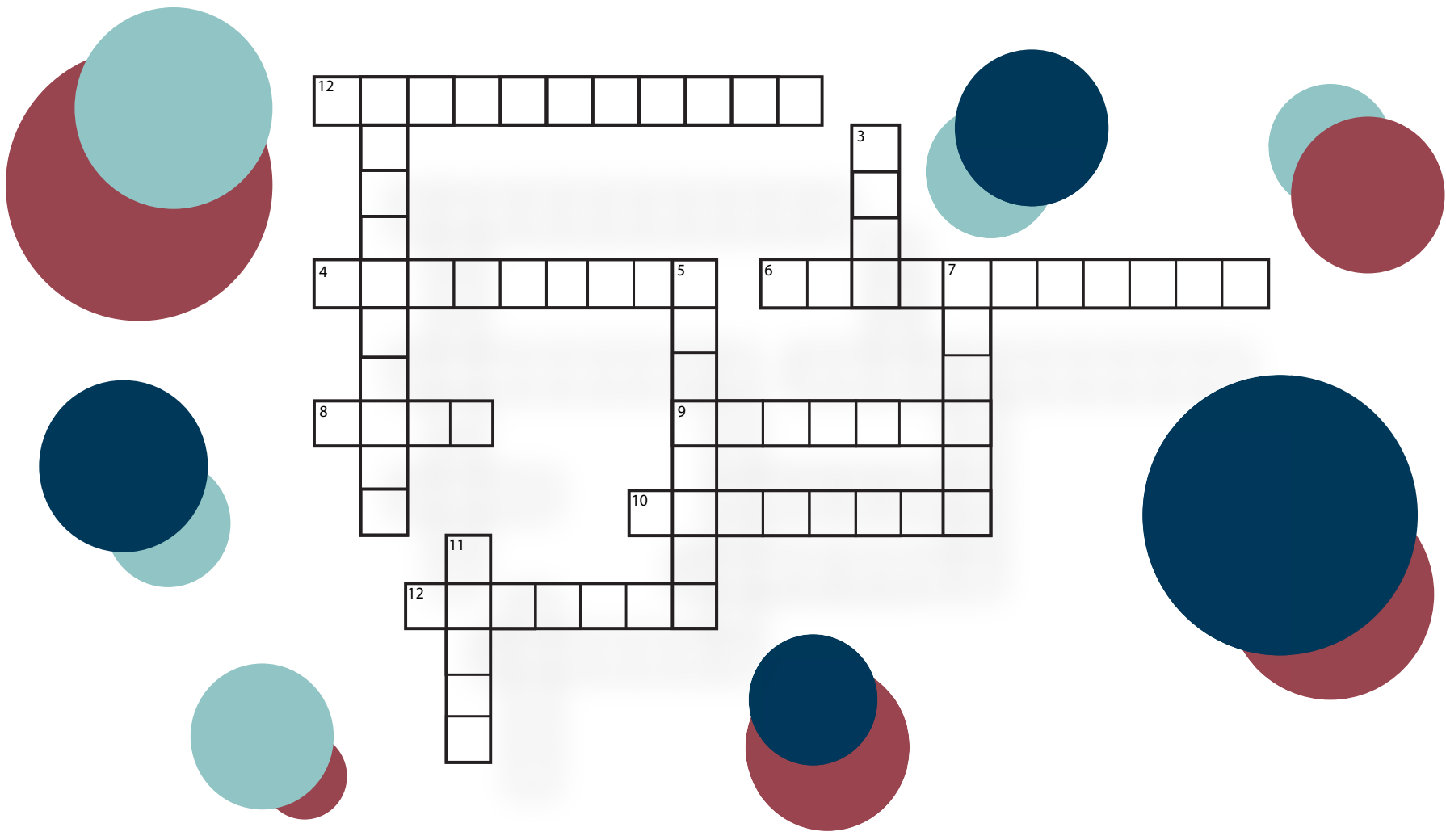

ACROSS

1 Abnormal low levels of water in the body

4 A specified time used to relax or take off from work or an activity

6 Setting a desired achievement

8 Designating a select variety of food and drinks to improve one's health

9 A habitual course of procedure- an unchanging formula

10 Organic compounds that can be found in foods to help increase nutritional value, and each plays a specific role in the body

12 A preventative action used to create or build immunity against a specific disease

DOWN

2 Brain produced substance that creates a painkiller effect on the body

3 A process of physical and mental discipline in which an individual is disconnected from worldly material

5 Body exertion with the goal of improving physical physique or health

7 A result from worry

11 A liquid drink needed for the survival of a living organism

WORD BANK: BREAKTIME, DEHYDRATION, DIET, ENDORPHINS, EXERCISE, GOALSETTING, ROUTINE, STRESS, VACCINE, VITAMINS, WATER, YOGA

Stimulus: A Medical Humanities Journal | Volume 1 | 2021 